\title{
GAMIFICANDO A EDUCAÇÃO AMBIENTAL: O DESAFIO JOGANDO VERDE NO INSTITUTO FEDERAL BAIANO
}

\author{
Adriana Melo Santos ${ }^{1}$ \\ Milton Ferreira da Silva Júnior ${ }^{2}$ \\ Elfany Reis do Nascimento Lopes ${ }^{3}$
}

Resumo: No campo da Educação Ambiental e da gamificação este estudo objetivou caracterizar e avaliar os resultados do Desafio Jogando Verde enquanto instrumento da Educação Ambiental em termos das competências e habilidades desenvolvidas pelos discentes. Evidenciou-se que a gamificação integrada à Educação Ambiental favorece uma construção coletiva de saberes, uma aprendizagem autônoma, criativa e crítica, além de fomentar a adoção de uma conduta consciente e sensível frente aos problemas ambientais. A conscientização ambiental após a estratégia gamificada Desafio Jogando Verde, ficou constatada, contribuindo para ampliação dos conhecimentos e a adoção de posturas favoráveis ao ambiente.

Palavras-chave: Jogos digitais; Tecnologia; Ambiente; Educação.

${ }^{1}$ Instituto Federal de Educação, Ciência e Tecnologia da Bahia. E-mail: adrianamelo@ifba.edu.br 2Universidade Federal do Sul da Bahia.

3 Universidade Estadual Paulista Júlio de Mesquita Filho. E-mail: elfany@posgrad.sorocaba.unesp.br Revbea, São Paulo, V. 11, № 1: 246-263, 2016. 


\section{Introdução}

A Educação Ambiental se mostra pertinente para uma gama possibilidades, especificamente para fortalecer a articulação entre 0 desenvolvimento sustentável e a conservação dos recursos naturais em nosso planeta. Com base nesta, é possível articular uma série de ações para trazer discussões pertinentes sobre a qualidade de vida dos indivíduos, da atual degradação ambiental que tem sido acometido os recursos naturais e como traçar estratégias para garantir um futuro qualificado do ambiente em que vivemos.

Há uma crença que a natureza pode ser definida e conquistada isoladamente do homem. Essa postura só reflete o desconhecimento sobre a interdependência entre sociedade e natureza, sendo necessário contestar essa maneira isolada por cada setor da sociedade, a fim de subsidiar o desenvolvimento de uma consciência direcionada à melhoria da qualidade de vida (NICOLESCU, 1999; MORAES, 2002).

No campo educacional, essas inquietações são percebidas, e têm conduzido a adoção de novos paradigmas educacionais, para a formação de indivíduos com competências e habilidades capazes de adequar-se às mudanças contínuas e propor soluções para os mais diversos problemas/cenários contemporâneos.

As questões que norteiam a prática docente na sala de aula ressaltam a necessidade de conectar-se a perspectiva mais interativa, pautada nas novas tecnologias e que ressignifica o papel do professor e dos alunos frente à construção do conhecimento. Somando-se ao contexto, as mudanças tecnológicas ocorridas provocaram alterações consideráveis no processo de como os jovens pensam, aprendem e processam as informações (PRENSKY, 2012).

Os jogos digitais têm assegurado no contexto educacional uma nova ferramenta de construção de conhecimento, aliado aos avanços tecnológicos e a fácil adaptação da nova "Geração C", caracterizada pela gama de jovens amplamente conectados, curiosos, investigativos, criativos e de fácil adaptação as novidades do mundo tecnológico (BAUMAN, 2007). Gros (2008) também assegura que os jogos digitais em sala de aula sempre motivam as crianças $\mathrm{e}$ jovens, pois conseguem aliar desafio, curiosidade e fantasia, aspectos que deveriam estar presentes dentro das escolas.

$O$ ato de jogar supõe uma ação, uma dinâmica própria, na qual o jogador apresenta mudanças em relação ao seu comportamento, aos seus sentimentos, à sua aprendizagem. Assim, o jogo cria uma predisposição para se aprender, ao criar situações de desafio e a aprendizagem adapta-se às necessidades e os estilos da geração atual e das futuras gerações (MOITA, 2007; PRENSKY, 2012). 
A utilização desse tipo de recurso didático voltado ao contexto ambiental é defendida por um crescente número de autores, confirmando a importância dos jogos no processo de ensino-aprendizagem (TAYLOR, 1994; FOGG, 2002; MENDES, 2006; MATOS, 2009; ZICHERMANN e CUNNINGHAM, 2011; ALVES, 2012; SHELDON, 2012; FARDO, 2013; CRUZ JUNIOR, 2013; MATTAR, 2015).

Ao imergir nesse universo, constata-se que a discussão sobre a temática cresce consideravelmente, transversalizando a sua utilização no setor educacional. Objetivou-se neste estudo caracterizar e avaliar os resultados do Desafio Jogando Verde enquanto instrumento da Educação Ambiental em termos das competências e habilidades desenvolvidas pelos discentes.

\section{O desafio Jogando Verde}

A gamificação é definida como o processo de utilizar o pensamento e as mecânicas dos games para envolver pessoas, motivar a ação, promover a aprendizagem e resolver problemas. Para fazer uso da gamificação, deve-se pensar nela como uma caixa de ferramentas, onde estão dispostos os elementos dos games, usando estratégias, métodos e pensamentos para resolver problemas nos mundos virtuais em situações do mundo real (FARDO, 2013).

Com base nas contribuições da gamificação, tem-se desde 2011, o desenvolvimento e aplicação da atividade gamificada Desafio Jogando Verde DJV, objetivando abordar os impactos ambientais causados pelo setor agropecuário, a partir de missões fundamentadas nos componentes curriculares do Curso Técnico em Agropecuária do Instituto Federal de Educação, Ciência e Tecnologia Baiano - IF BAIANO, campus Teixeira de Freitas.

O jogo é ambientado na comunidade Gaia, baseada nos pilares da Agroecologia, que sofre uma conspiração de um Produtor Rural, do Prefeito e da representante da Indústria Minera Mais, que visam a implantação de uma Mineradora na referida área. Para evitar a implantação, a comunidade organiza uma missão técnica e contrataram dois profissionais para emitirem os pareceres favoráveis quanto à desapropriação, são eles: um Técnico em Agropecuária e um Técnico em Florestas (Figura 1). 

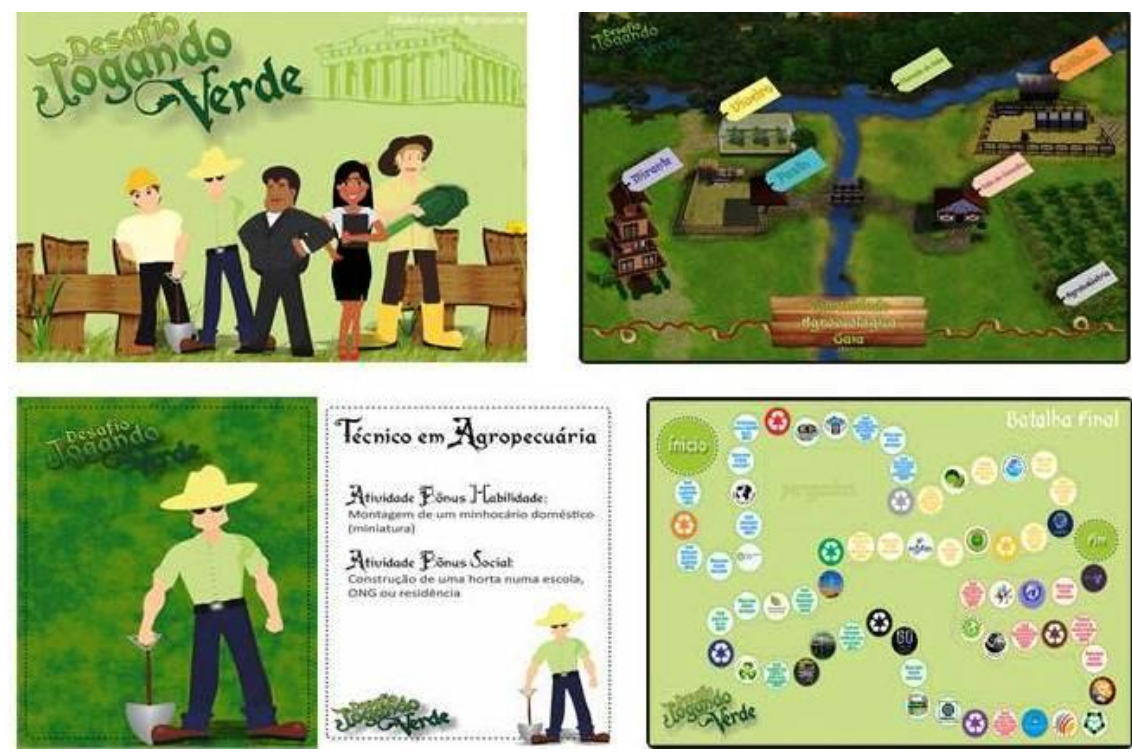

Figura 1: Ambiente e Cenário do Desafio Jogando Verde.

Os jogadores tornam-se os profissionais contratados e realizam missões para atingir a meta de libertar a comunidade Gaia. Essas missões contemplam quiz, seleção e reflexão sobre animais domésticos e silvestres, estudos relacionados às distintas áreas de formação do técnico agropecuária, dentre eles, a legislação ambiental, nutrição de animais, classificação de plantas, utilização de equipamentos e maquinários, classificação de atitudes positivas e negativas sobre 0 uso de agrotóxicos e compostagem, monocultura, assoreamento dos rios e queimadas, harmonização do tipo e preparo do solo para o plantio de culturas.

A batalha final consiste um jogo de tabuleiro com perguntas sobre os principais eventos, programas e ações voltadas a preservação do meio ambiente (Clube de Roma, ECO/92, Rio + 10, Rio + 20, Conferência de Estocolmo, Carta da Terra, Protocolo de Kyoto, Conferência de Copenhague, Política Nacional dos Resíduos Sólidos, Política Nacional de Educação Ambiental, Coleta seletiva, 5 R's, Desenvolvimento sustentável, ISO 4001, Maremotriz, Agenda 21, Parque eólico, Permacultura, Biomassa, Logística reversa, A hora do planeta, Ecoloft, Aquecimento global, Conferência de Durban contra racismo, Consumo verde e Maquiagem verde ambiental), além de ter exemplos de comportamentos diários que podem prejudicar e favorecer 0 ambiente.

Deve-se ressaltar que o game foi elaborado justificado pela busca por um modelo de produção agrícola sustentável, apoiado nas concepções de Manucci (2012), ao argumentar que optar pela manutenção do agronegócio é prender-se a um sistema sem a noção clara de ambiente e da necessidade de sua proteção.

Ainda assim, mesmo que a Educação Ambiental seja colocada como um tema transversal tanto para a concepção do curso de técnico em agropecuária, 
quanto para a formação destes profissionais, não se visualizou ações efetivas de desenvolvimento dessas abordagens pelos docentes e estudantes, de modo que, a reflexão sobre a problemática ambiental e a sustentabilidade no âmbito da produção agrícola encontra-se comprometida durante a formação dos estudantes.

\section{Metodologia}

\section{Área e sujeitos da pesquisa}

O Instituto Federal de Educação, Ciência e Tecnologia Baiano- IF Baiano é uma autarquia consolidada, como Instituição, a partir da integração das Escolas Agrotécnicas Federais da Bahia e das Escolas Médias de Agropecuária Regional da CEPLAC (Comissão Executiva do Plano da Lavoura Cacaueira), a saber: Catu, Santa Inês, Guanambi, Senhor do Bonfim, Uruçuca, Valença, Itapetinga e Teixeira de Freitas. Além dos campi de Bom Jesus da Lapa e Governador Mangabeira.

O Campus Teixeira de Freitas, lócus desse estudo, centraliza-se numa região composta por vinte e um municípios (Alcobaça, Belmonte, Caravelas, Eunápolis, Guaratinga, Ibirapuã, Apebi, Itagimirim, Itabela, Itamaraju, Itanhém, Jucuruçu, Lajedão, Medeiros Neto, Mucuri, Nova Viçosa, Porto Seguro, Prado, Santa Cruz Cabrália, Teixeira de Freitas Vereda) que formam o Território Extremo Sul da Bahia. Oferece cursos técnicos de Agropecuária, Florestas e Hospedagem nas diversas modalidades integrado (ensino médio junto com a formação técnica) e/ou subsequente (exige-se o ensino médio concluído) (BRASIL, 2008).

A amostra pesquisada foi constituída por estudantes do curso Técnico em Agropecuária, na modalidade Integrada, do IF Baiano, campus Teixeira de Freitas, de ambos os sexos, uma vez que na região de abrangência do IF BAIANO Campus Teixeira de Freitas, há uma significativa área rural cultivada, caracterizada pela diversificação de atividades produtivas. O critério utilizado para definição da amostra teve como base a seleção de $20 \%$ dos estudantes regularmente matriculados no ano letivo de 2014, a partir de sorteio aleatório em turmas do curso integrado de Técnico em Agropecuária (Tabela 1).

Tabela 1: Faixa etária dos estudantes do Curso Técnico em Agropecuária - IF Baiano Campus Teixeira de Freitas - Teixeira de Freitas/BA, 2014. $(n=25)$

\begin{tabular}{lccc}
\hline & $1^{\circ}$ Ano & $2^{\circ}$ Ano & $3^{\circ}$ Ano \\
\hline Número de alunos & 11 & 11 & 3 \\
\hline Total & \multicolumn{4}{c}{25} \\
\hline
\end{tabular}

Fonte: Dados da Pesquisa. 


\section{Abordagem, coleta e análise de dados}

Este estudo está ancorado na pesquisa qualitativa, abordando as aprendizagens e mudanças de comportamento de estudantes por meio da realização de um estudo de caso. Os dados foram coletados por meio de aplicação de questionário e grupo focal. $O$ questionário sobre a conscientização ambiental dos sujeitos da pesquisa foi adaptado de Chiamenti (2003), buscando avaliar a conscientização prévia do entrevistado, anteriormente à utilização do jogo. Em seguida, o Desafio Jogando Verde foi realizado nas dependências do campus e, em seguida, o mesmo questionário foi reaplicado, visando identificar/comparar as nuances relacionadas à conscientização ambiental.

O grupo focal é definido como uma abordagem qualitativa, não diretiva, inspirada em técnicas de entrevistas não direcionadas, constituído por um número pequeno de pessoas, onde ocorre à participação e a interação de todos a fim de debater um tema fornecido pelo moderador (GATTI, 2005). O Grupo Focal foi realizado a fim de avaliação da referida estratégia gamificada para a conscientização ambiental dos sujeitos envolvidos.

Os dados foram analisados segundo a análise descritiva e a análise de conteúdo, definida como uma técnica capaz de tratar dados qualitativos e quantitativos, fazendo uma análise das comunicações por procedimentos sistemáticos e objetivos de descrição do conteúdo das mensagens, para compreender o fenômeno estudado (BARDIN, 2009).

Conforme dispõe a Resolução nำ196/CNS/MS (BRASIL, 19996) visando garantir a integridade ética da pesquisa que envolve seres humanos, esta pesquisa foi submetida e aprovada pelo Comitê de Ética em Pesquisa da Universidade Estadual de Santa Cruz/UESC sob o número de registro 34483414.0.0000.5526.

\section{Resultados e Discussão}

A percepção dos entrevistados representa o olhar sobre a área profissional a qual estão inseridos com as questões ambientais. As autoras Teixeira e Sammarco (2014) salientam que a percepção pode ser usada como ferramenta para a Educação Ambiental, tornando o ser humano mais apto a enfrentar problemas socioambientais através de valores éticos, culturais e políticos.

A opinião dos sujeitos pesquisados sobre práticas ambientais relacionadas aos processos do setor agropecuário é expressa na Figura 2. Os resultados relevam que os estudantes reconhecem o impacto das atividades agropecuárias inicialmente como moderados, observou-se que após o DJV há uma ampliação dessa percepção para uma atividade de grande impacto ambiental.

A reflexão sobre esta temática pode estar atrelada as estratégias apresentadas no jogo, através da apresentação e reflexão de danos

revista brasileira educação ambiental 
provocados pelo setor. As respostas são consonantes com os pensamentos de Fernandez Neto e Sarcinelli (2009) quando classificam as atividades agrícolas como as principais fontes de contaminação dos recursos naturais.

O reconhecimento dos reflexos da produção agrícola pode ser considerado o primeiro passo rumo ao processo mais amplo que objetiva 0 engajamento dos sujeitos pesquisados em prol do ambiente (Figura 3).

Evidenciou-se que após a realização do DJV assimilaram com maior clareza a grande importância de serem protagonistas de mudanças ambientais. Esta postura de acordo com Ribeiro (2003) é importante, pois cidadania e sustentabilidade estão interligadas, numa espécie de fonte de novas ideias e valores extraídos a partir da cautelosa observação do ambiente.

Considerando o que Freire (1997) pondera sobre a educação enquanto um elo que permite estabelecer uma relação de complexidade com a natureza, observa-se uma ação diretiva no Desafio Jogando Verde ao problematizar a realidade e interligar a realidade em todas as suas formas.

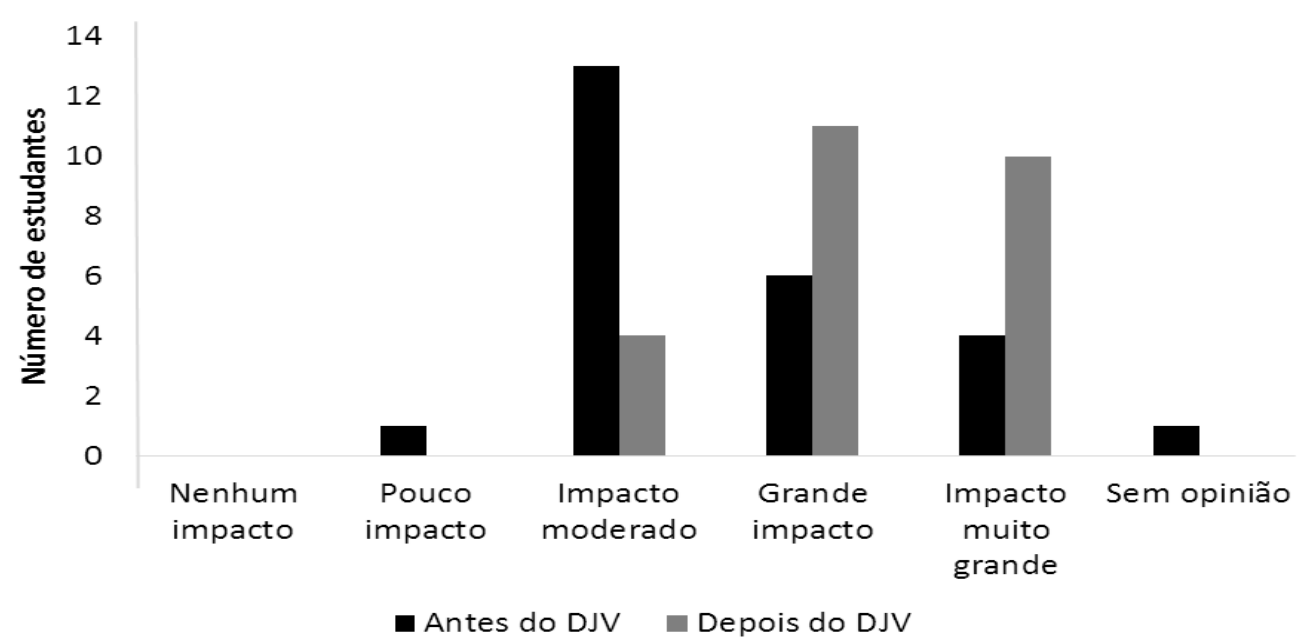

Figura 2: Opinião dos estudantes do Curso Técnico em Agropecuária - IF Baiano Campus Teixeira de Freitas - Teixeira de Freitas/BA sobre o grau de impacto ambiental gerado nas atividades de produção agrícola, $2014(n=25)$. Fonte: Dados da pesquisa. 


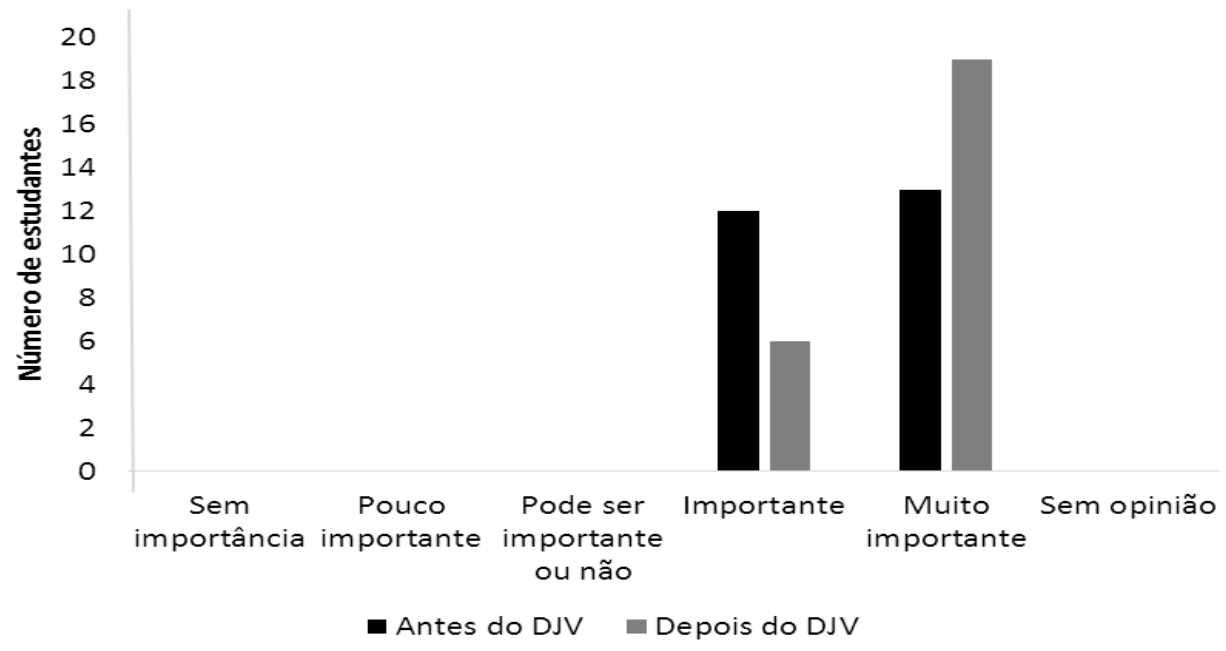

Figura 3: Opinião dos estudantes do Curso Técnico em Agropecuária - IF Baiano Campus Teixeira de Freitas - Teixeira de Freitas/BA sobre a importância do técnico em agropecuária desenvolver atividades de proteção ambiental, $2014(\mathrm{n}=25)$.

Fonte: Dados da pesquisa.

Ao discutir a percepção do ser humano como parte integrante de um sistema maior e em constante transformação, a Figura 4 enfatiza a competitividade no mercado de trabalho, aludindo assim, a vida cotidiana e a habilidade dos estudantes em trabalharem em equipe, praticarem a cooperação e aprimorarem as relações interpessoais.

Constatou-se que a rivalidade é considerada a marca registrada de tais relações e após o DJV essa percepção foi acentuada, reflexo da configuração da atividade. O modelo de desenvolvimento do jogo, e a necessidade de reflexão em equipes, a fim de atingir o objetivo final do DJV revelou que abordagens pedagógicas deste tipo apresentam importância no processo de aprendizagem, uma vez que, despertam o sentido da solidariedade, coletivismo e a construção conjunta do conhecimento.

Sabendo que o desempenho de cada equipe não seria utilizado como parâmetro para avaliação e que não haveria perdedores no DJV, contribuiu para que a atividade atingisse seus objetivos no aspecto educacional, sendo o conhecimento convertido para a formação do indivíduo quanto profissional capacitado, crítico e reflexivo. 


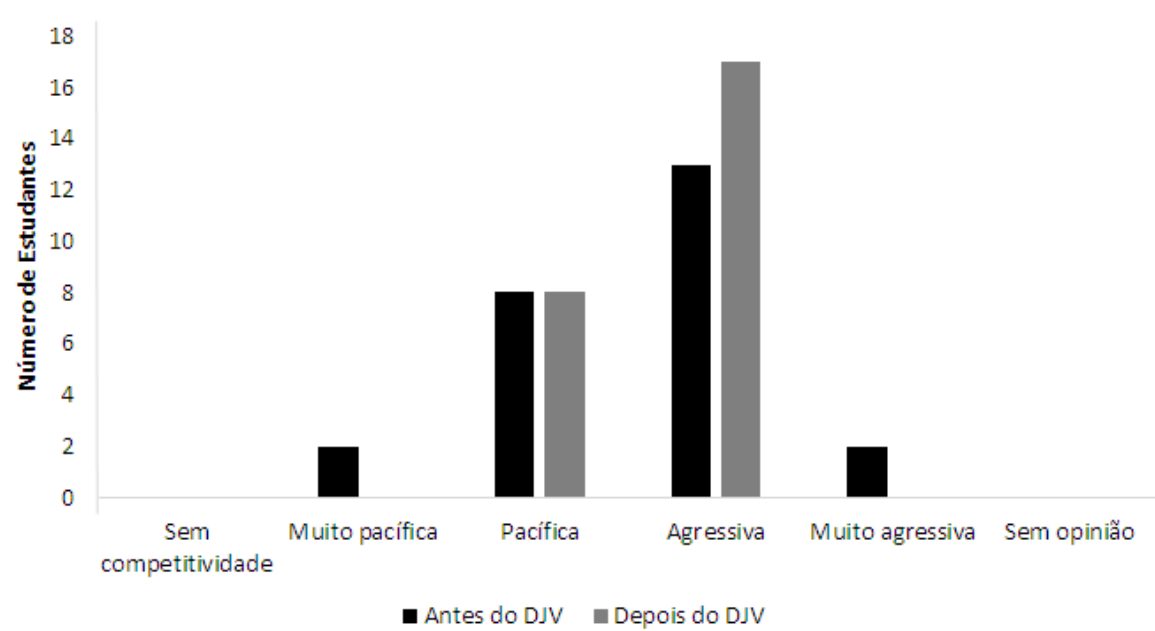

Figura 4: Opinião dos estudantes do Curso Técnico em Agropecuária - IF Baiano Campus Teixeira de Freitas - Teixeira de Freitas/BA em relação à competitividade no mercado de trabalho para o técnico em agropecuária, $2014(n=25)$.

Fonte: Dados da pesquisa.

Verificou-se que mesmo o DJV abordando técnicas alternativas de produção sustentável em detrimento dos agrotóxicos, não houve uma mudança expressiva da opinião dos entrevistados após sua utilização, sendo recomendável ratificar as informações em torno da temática para que resultados positivos sejam conquistados.

Consideraram ainda, que dentre os fatores que são responsáveis pela ampla utilização desses produtos, está o desconhecimento dos riscos associados a sua utilização, a não observância das normas de segurança, o livre comércio e a pressão exercida pelos distribuidores destes, aliados à deficiência da assistência técnica ao homem do campo e a ausência de fiscalização do cumprimento das leis.

Se não é falta de conhecimento, qual seria o motivo para o uso de agrotóxicos? Buscando elucidar tal questionamento, Londres (2015) enfatiza que a agricultura convencional não assume os custos ambientais e sociais por ela gerada. Quem paga, na prática, pelas contaminações ambientais e intoxicações provocadas por este modelo de produção é a sociedade.

Nesse sentido, a justificativa alicerçada na necessidade de produzir em detrimento aos danos ambientais, não é validada pela maioria dos estudantes que participaram do DJV (Figura 5). Cabe a proposição de uma nova investigação visando refletir os motivos pelos quais recorrem a tais métodos e como medida de curto prazo, fomentar campanhas de alerta dos danos à saúde humana e promoção de controles alternativos de pragas, como por exemplo, os enfatizados no DJV. 


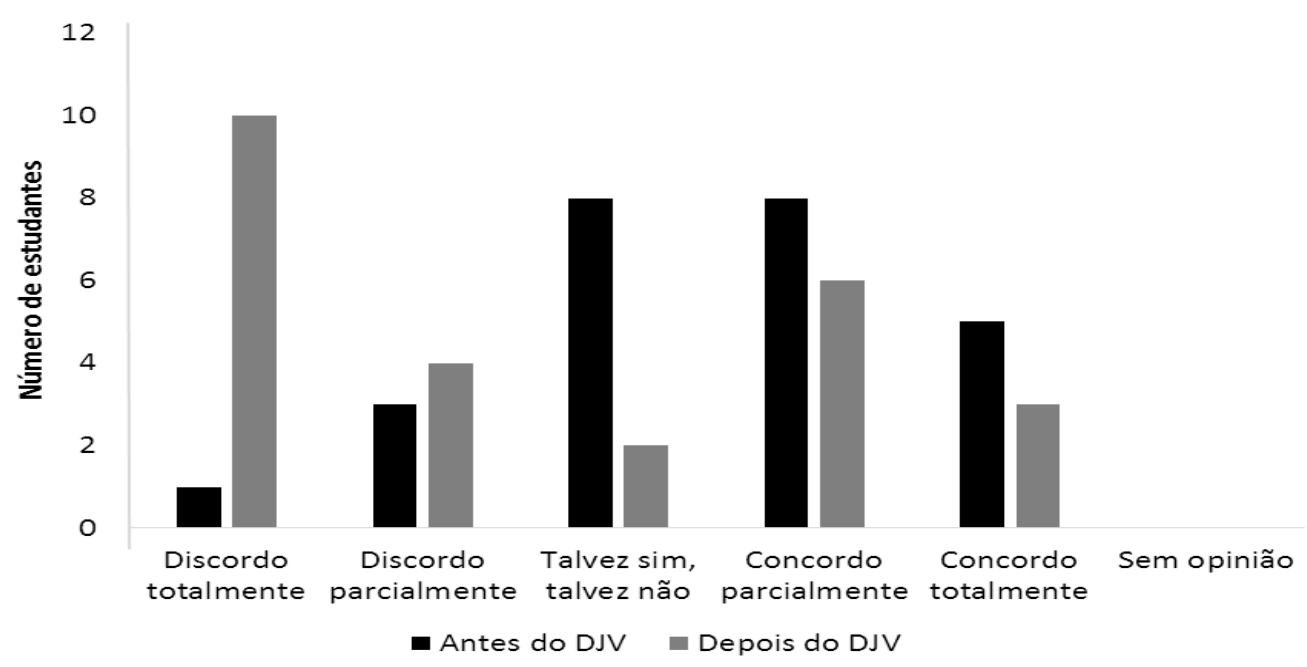

Figura 5: Opinião dos estudantes do Curso Técnico em Agropecuária - IF Baiano Campus Teixeira de Freitas - Teixeira de Freitas/ sobre a afirmativa de que os produtores rurais sabem que os agrotóxicos causam grandes danos ao meio ambiente, mas precisam produzir, $214(n=25)$. Fonte: Dados da pesquisa.

O desconhecimento sobre as leis ambientais foi alternativa para o questionamento, e observa-se que antes da atividade gamificada, havia uma incerteza ao afirmar ou contestar a falta de conhecimento como causa da problemática, mas após a aplicação do DJV os estudantes arriscaram-se a discordar parcialmente dessa afirmação (Figura 6). Para os autores Fernandez e Garcia (2001) os ecossistemas são mantidos a partir do conhecimento da legislação ambiental.

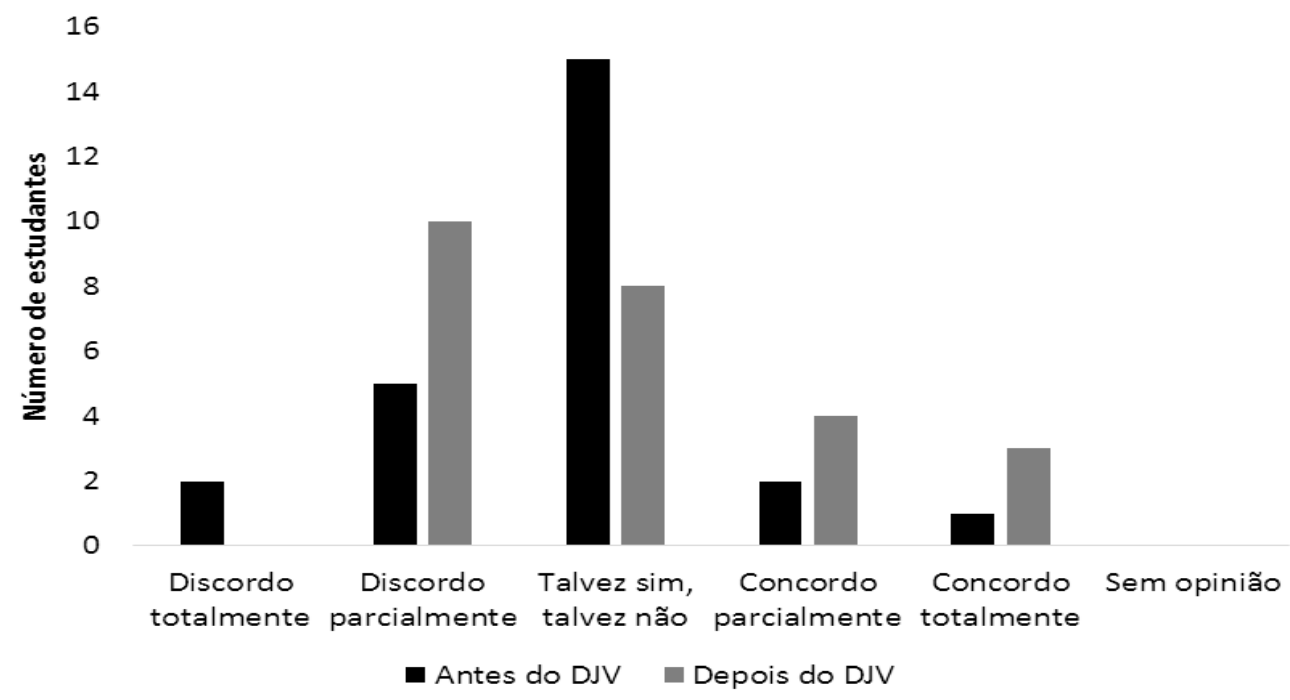

Figura 6: Opinião dos estudantes do Curso Técnico em Agropecuária - IF Baiano Campus Teixeira de Freitas - Teixeira de Freitas/BA sobre o não conhecimento dos produtores rurais das leis de proteção ambiental, $2014(\mathrm{n}=25)$.

Fonte: Dados da pesquisa. 
A crença de que não serão multados diante dos danos ambientais causados por sua atividade, foi identificada a partir do fato dos estudantes preferirem não afirmar e nem responder negativamente ao questionamento, confirmando a necessidade de propor ações mais elucidativas no DJV durantes as missões (Figura 7).

Os resultados revelaram também, que os entrevistados classificam os conhecimentos ambientais disponibilizados pelo curso como suficientes (Figura 8). Acredita-se que o fato de formar as equipes para a realização do DJV, articulando as equipes com membros de todas as turmas/anos, possa ter representado uma maior facilidade na realização das missões, influenciando assim, a percepção de domínio dos conteúdos em questão.

Infelizmente, essa hipótese não poderá ser testada numa próxima aplicação, pois a separação por turma/ano implicaria em anular a interdisciplinaridade com a qual o DJV foi proposto, negligenciando a configuração de comunidades de aprendizagem estabelecidas pelas trocas de conhecimentos durante a aplicação.

O tema adquiriu importância nos sistemas de ensino devido à reorientação curricular produzida pelo Ministério da Educação, por meio dos Parâmetros Curriculares Nacionais (BRASIL, 1996), nos quais, a temática sobre o Meio Ambiente foi incluída como um dos temas transversais e com a promulgação da Política Nacional de Educação Ambiental (BRASIL, 1999) que dispõe sobre a introdução da Educação Ambiental no ensino formal.

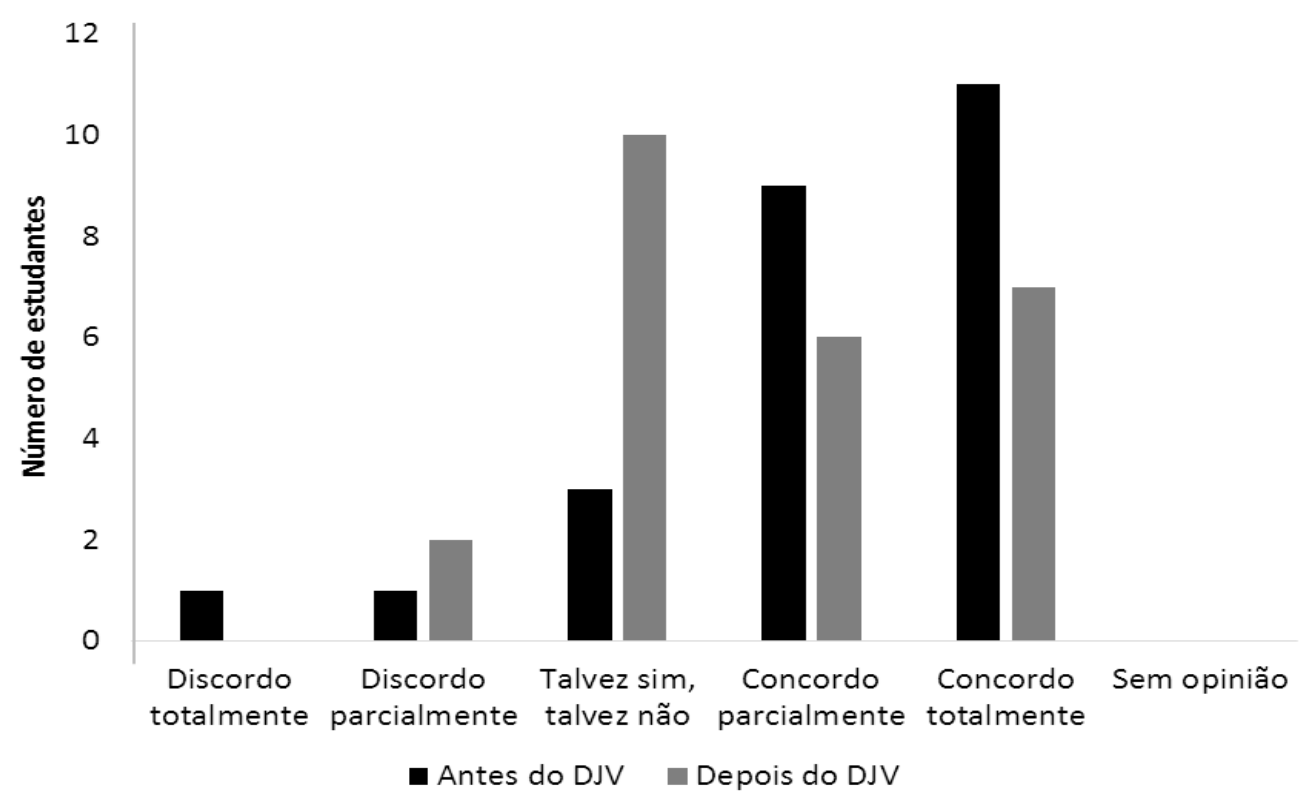

Figura 7: Opinião dos estudantes do Curso Técnico em Agropecuária - IF Baiano - Campus Teixeira de Freitas - Teixeira de Freitas/BA sobre multas em caso de agressão ambiental, $2014(n=25)$. Fonte: Dados da pesquisa. 


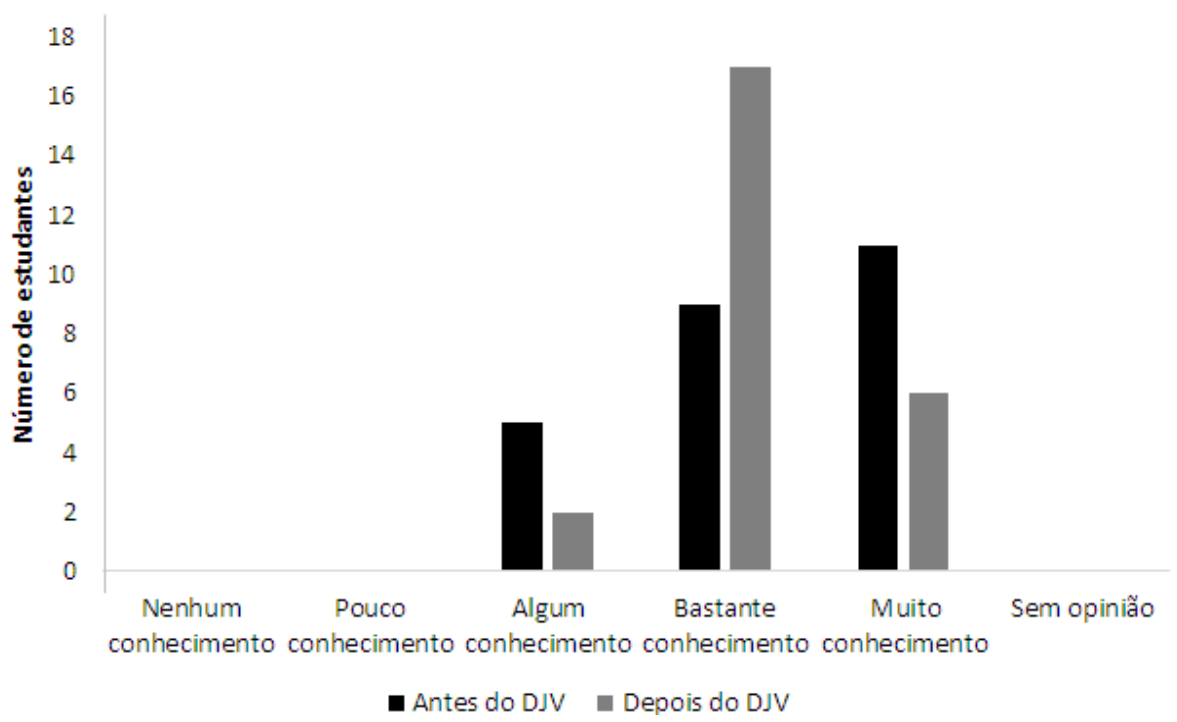

Figura 8: Opinião dos estudantes do Curso Técnico em Agropecuária - IF Baiano Campus Teixeira de Freitas - Teixeira de Freitas/BA sobre o grau de conhecimento ambiental adquirido nas disciplinas do curso, $2014(n=25)$.

Fonte: Dados da pesquisa.

A Figura 9 retrata o nível de envolvimento dos entrevistados como atores sociais, percebendo-se que não faz parte da rotina dos entrevistados participarem de discussões em conselhos, comunidades e associações. Os resultados apresentados sobre esta variável corroboraram com o pensamento de Ajzen (1991), ao afirmar que o comportamento do indivíduo pode ser mensurado a partir da análise das pressões sociais e dos sentimentos pessoais, pois a responsabilidade moral social determinará seu nível de comprometimento na resolução das questões ambientais.

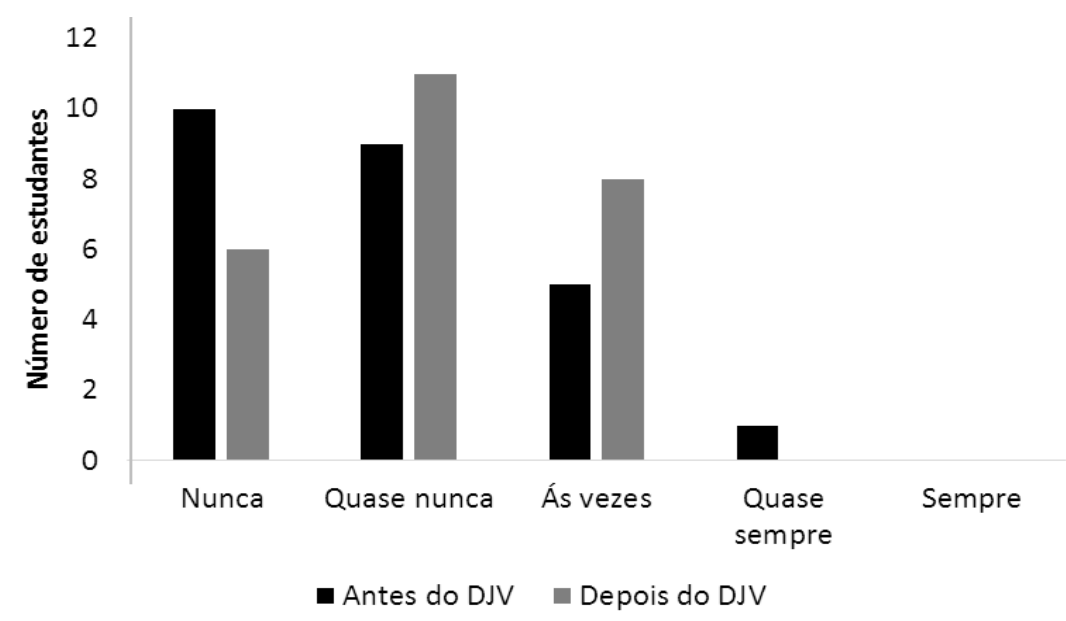

Figura 9: Grau de participação dos estudantes do Curso Técnico em Agropecuária - IF Baiano - Campus Teixeira de Freitas - Teixeira de Freitas/BA em reuniões de sua comunidade para discutir problemas sociais, $2014(n=25)$. Fonte: Dados da pesquisa. 
O DJV encontra-se também, em consonância com o que foi preconizado também por Marin (2003), na qual a educação é considerada o único instrumento capaz de despertar novas reflexões e comportamentos, uma vez que, apenas no instante em que o indivíduo reflete sobre o seu lugar na paisagem percebida, é assim, se torna possível a avaliação e a mudança de suas ações.

O comportamento ambientalmente responsável reflete o nível de comprometimento dos sujeitos com as questões ambientais. Os entrevistados discordam totalmente de que a comunidade deve receber pagamento por engajar-se em questões ambientais (Figura 10).

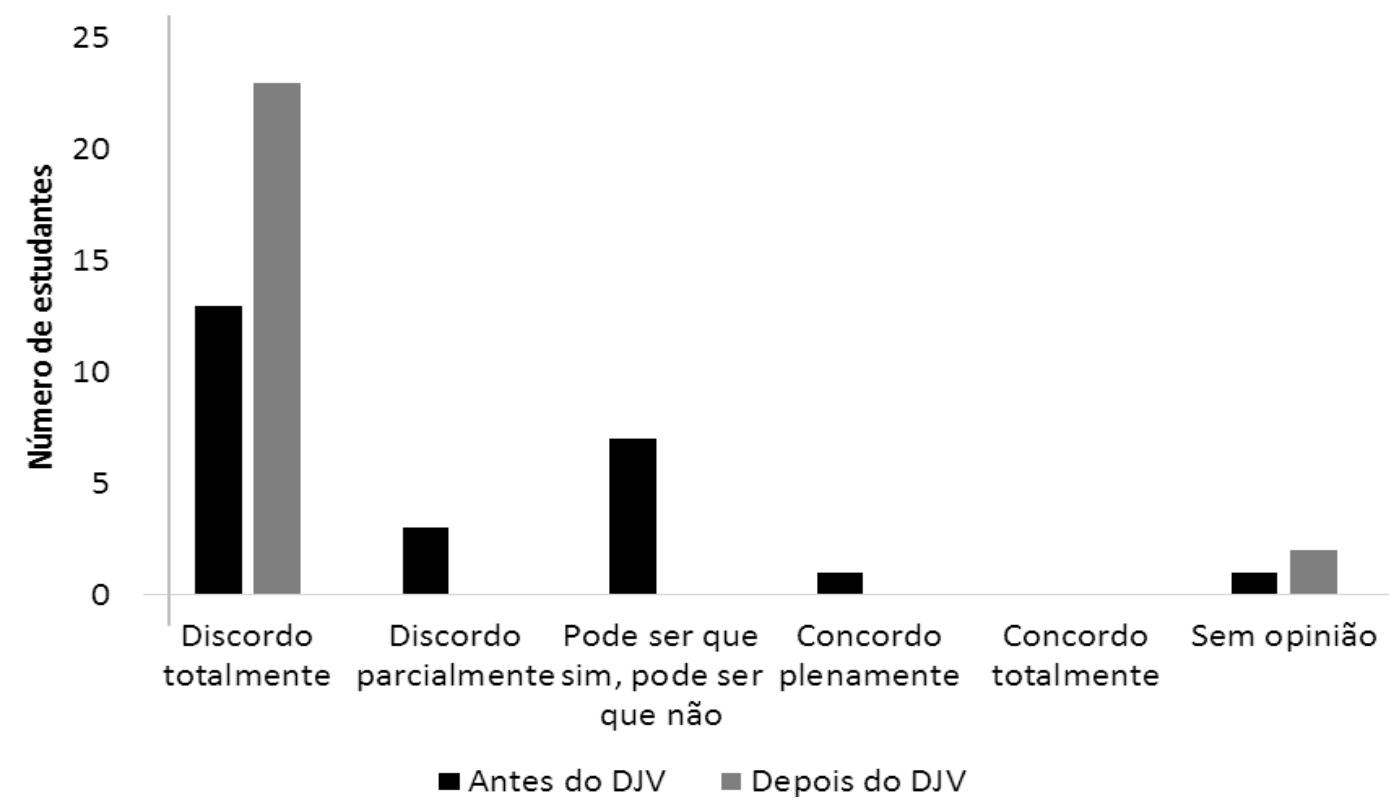

Figura 10: Opinião dos estudantes do Curso Técnico em Agropecuária - IF Baiano Campus Teixeira de Freitas - Teixeira de Freitas/BA sobre a situação em que a comunidade só deveria participar de um programa para despoluir um rio, por exemplo, caso recebesse do governo um benefício em troca, $2014(n=25)$.

Fonte: Dados da pesquisa.

O DJV contribuiu com a ampliação do comprometimento dos sujeitos pesquisados com as questões ambientais, a partir do momento que propôs as atividades bônus. As atividades bônus representavam metas voltadas à Educação Ambiental no contexto agropecuário e da atuação socioambiental do técnico em agropecuária, dentre elas, a consultoria voluntária em propriedade rural, construção de minhocário e hortas comunitárias em escolas, atividade voluntária em ONGs de animais silvestres e a confecção de panfletos sobre o reaproveitamento de alimentos.

A Figura 11 exemplifica como os sujeitos pesquisados se sentem frente à atuação do outro em um contexto de problema ambiental. Observou-se que os estudantes se mostraram incomodados com a postura do outro, sugerindo a adesão de um comportamento ambientalmente correto. De acordo com Maria 
(2000), a qualidade do ambiente só será alcançada com a harmonização das relações estabelecidas entre sociedade, governo, instituições de ensino e pesquisa, a partir da reflexão de atitudes coletivas que elevem a qualidade do ambiente em função de reparação de atitudes incorretas e do dever coletivo de cuidado com a qualidade do ambiente.

Os resultados observados pela utilização do DJV como estratégia pedagógica gamificada buscaram mensurar a conscientização ambiental dos sujeitos pesquisados, podendo ser considerada positiva, uma vez que estimularam a reflexão e ação frente ao ambiente.

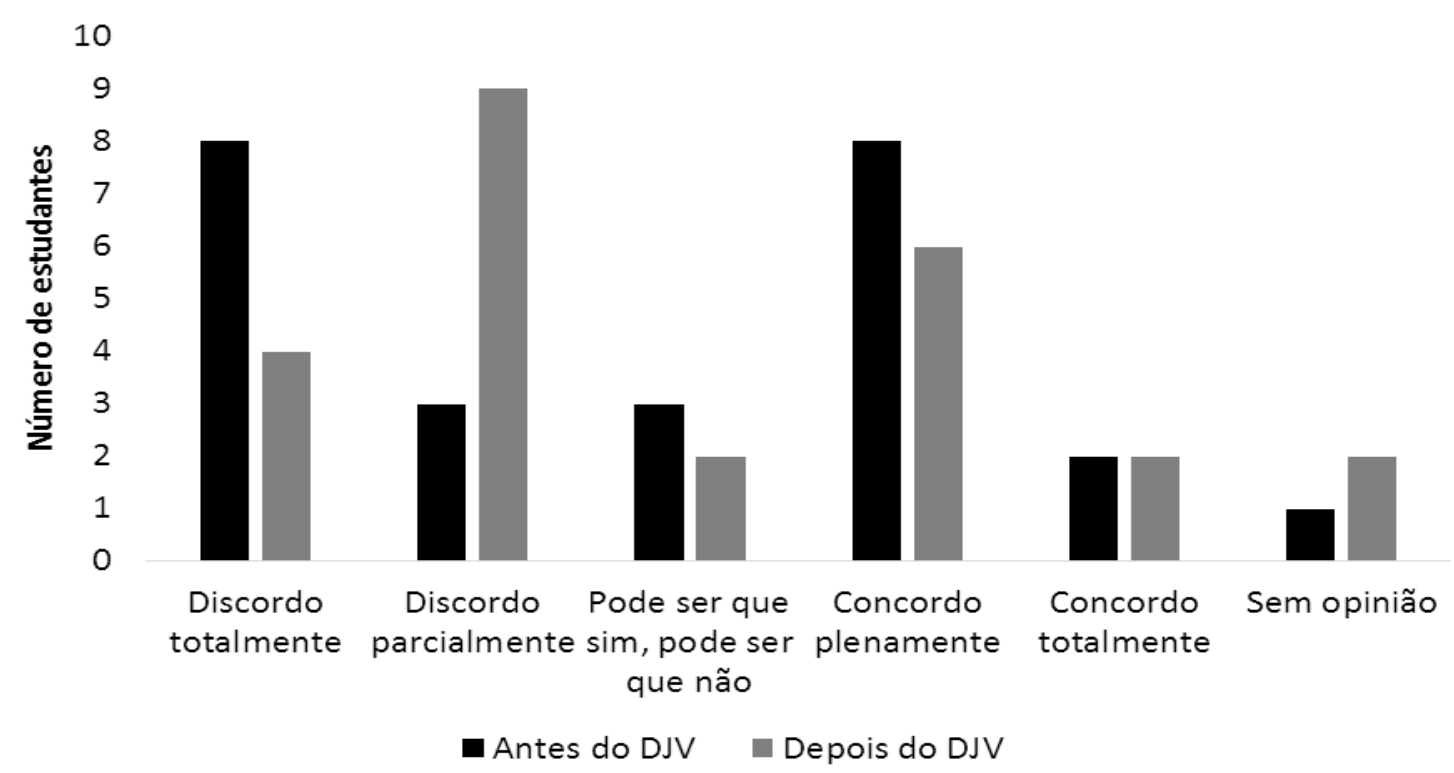

Figura 11: Opinião dos estudantes do Curso Técnico em Agropecuária - IF Baiano Campus Teixeira de Freitas - Teixeira de Freitas/BA sobre a sensação de sentir-se um bobo quando, para economizar, deixa de lavar o carro com água encanada, e vê que seu vizinho continua lavando o carro com a mesma água, $2014(n=25)$. Fonte: Dados da pesquisa.

\section{Contribuição do Desafio Jogando Verde (DJV) à conscientização ambiental}

O grupo focal realizado permitiu mensurar a percepção dos participantes frente à contribuição do Desafio Jogando Verde para a formação dos futuros técnicos em agropecuária. Fazer a escuta dos atores envolvidos consistiu em um processo importante para confirmar o DJV como uma estratégia de construção coletiva de conhecimentos, registrando as impressões observadas, ao mesmo tempo em que ressaltava a importância de identificar as relações e o conhecimento construido. Essa etapa reforça também, que o DJV compõe uma etapa do aprendizado e que as ações não terminam no "ato de jogar", mas compõe uma estratégia educativa para a construção do conhecimento, uma autoavaliação tanto por parte do estudante, quanto para a prática pedagógica do educador. 
Constatou-se que as missões propostas pelo DJV priorizam a reflexão sobre a atitude a ser tomada para que possam resgatar os personagens, já que, só são aceitos comportamentos ambientalmente responsáveis e também são condenados posturas que são danosas ao ambiente.

A cooperação entre os integrantes das equipes foi a chave para a realização das atividades propostas na estratégia educacional gamificada, no qual, o comprometimento em escolher as melhores alternativas para progredirem no desafio foi essencial.

O senso de comunidade respaldou-se nas missões bônus que foram disponibilizadas aos estudantes durante o jogo, apesar da necessidade de fundamentar a importância dessa participação ao longo da prática profissional. $\mathrm{Da}$ mesma forma, os aspectos legais atingiram o nível suficiente de conscientização, mas foi sugerida uma ênfase sobre os efeitos legais de práticas de degradação ambiental.

A experiência de participar de uma gamificação foi considerada interessante e gratificante para os estudantes, a oportunidade de aprender de forma divertida sobre a conscientização ambiental. O jogo DJV foi avaliado como atrativo e educativo, permitindo reforçar hábitos que devem ser diários tanto na vida pessoal, como na profissional.

Os estudantes ao relacionar o DJV e os conteúdos apresentados nas disciplinas que cursam, ratificaram a associação entre ambos, aliando teoria e prática de forma interativa para favorecer uma aprendizagem eficaz. Os estudantes foram taxativos ao afirmar que o jogo promove a reflexão da necessidade de produzir de maneira sustentável e da mudança de atitudes em relação à problemática ambiental.

Em relação à apresentação de algum conhecimento novo relacionado à temática, foram destacados a importância do trabalho em equipe e os aspectos relacionados à preservação ambiental, que em alguns momentos são negligenciados durante o curso. Salientaram também, que as situações apresentadas no DJV fazem parte do cotidiano profissional do técnico em agropecuária e a narrativa tornou o mesmo bem envolvente, despertando-os a passar para a próxima etapa e assim concluir o que foi proposto como desafio.

Quando inquiridos se o DJV poderia influenciar na mudança de comportamento em relação à problemática ambiental alguns estudantes mostraram-se indecisos em afirmar que haveria mudanças. Importante ressaltar que essa visão não foi em nenhum momento colocada como ineficácia do DJV, mas associada da ganância dos homens em relação à forma como conduzem a sociedade, a economia e a exploração dos recursos naturais.

Outros estudantes confirmaram que após a conscientização proporcionada pelo DJV, haveria mudança efetiva de comportamento, pois sinalizam as intervenções necessárias para minimizar os impactos da agricultura sobre o meio ambiente. 
Os estudantes evidenciaram que antes possuíam um pensamento superficial sobre a interação homem-natureza, e posteriormente, agregaram em sua formação direcionamentos sobre como a escolha do método produtivo errado pode ocasionar danos ambientais consideráveis, outros demonstraram satisfação em interagir com colegas de turmas avançadas, tendo contato com conhecimentos que serão adquiridos institucionalmente nos anos subsequentes do curso.

Com estas percepções, pode-se afirmar que o Desafio Jogando Verde foi considerado uma estratégia de Educação Ambiental crítica efetiva. De forma contrária à Educação Tradicional, a Educação Ambiental Crítica volta-se para uma ação reflexiva (teoria e prática - práxis) de intervenção em uma realidade complexa; além dos livros e dos muros das escolas.

É uma Educação política voltada para a transformação da sociedade em busca da sustentabilidade. Assim, como nos disse Paulo Freire, essa é uma "Pedagogia da Esperança", capaz de construir utopias, como um "inédito viável", por aqueles que têm a firmeza da renúncia e a coragem de inovar. Pois são justamente esses que têm a possibilidade de contribuir para a construção de um mundo melhor (GUIMARÃES, 2004).

\section{Conclusão}

O estudo evidenciou que a gamificação integrada à Educação Ambiental favorece uma construção coletiva de saberes, uma aprendizagem autônoma, criativa e crítica, além de fomentar a adoção de uma conduta consciente e sensível frente aos problemas ambientais.

A conscientização ambiental antes e após a estrategia gamificada Desafio Jogando Verde, ficou confirmada com a ampliação dos conhecimentos sobre os danos ambientais oriundos da agropecuária, bem como alternativas sustentaveis para o setor. O DJV ratificou ainda que a adoção de posturas favoráveis ao meio ambiente configura-se tanto como um aspecto ético essencial ao exercício da cidadania, quanto como um diferencial no mercado de trabalho, tendo em vista a expansão da agricultura sustentável.

\section{Referências}

ALVES, P.F. et al. A rede social móvel Foursquare: uma análise dos elementos da gamificação sob a ótica dos usuários. 2012, 8 f. Disponível em: < http://ceur-ws.org/Vol-980/paper3.pdf > Acesso em: 05 Jun 2015.

BARDIN, L. Análise de Conteúdo. Portugal, Edições 70, 2009.

BAUMAN, Z. Vida líquida. Rio de Janeiro, Jorge Zahar Ed., 2007.

BRASIL. Lei n. 9.394 de 20 de dezembro de 1996. Estabelece as diretrizes e bases da educação nacional. Brasília, DF, 1996. 
BRASIL. Ministério da Saúde (MS). Conselho Nacional de Saúde (CNS). Resolução n. 196 de 10 de outubro de 1996. Dispõe sobre diretrizes e normas regulamentadoras de pesquisas envolvendo seres humanos.

BRASIL. Lei n. 9795 de 27 de abril de 1999. Dispõe sobre a Política Nacional de Educação Ambiental. Brasília, DF, 1999.

CHIAMENTI, A.M.M. Gestão Ambiental na Agricultura: um estudo sobre fatores associados à conscientização ambiental em estudantes de uma escola agrotécnica. 2003. 131f. Dissertação (Mestrado em Engenharia de Produção) Universidade Federal do Rio Grande do Norte, Natal, 2003.

CRUZ JUNIOR, G. Entre bolas, cones e consoles: desafios dos jogos digitais no contexto da Mídia-Educação (Física). Revista Atos de Pesquisa em Educação, Blumenau, v. 8, n. 1, p. 287-305, 2013.

FARDO, M.L. A gamificação aplicada em ambientes de aprendizagem. Revista Novas Tecnologias na Educação, Porto Alegre, v. 11, n. 1, p. 1-9, 2013.

FERNANDEZ, X S.; GARCIA, D.D. Desenvolvimento rural sustentável: uma perspectiva agroecológica. Revista Agroecologia e Desenvolvimento Rural Sustentável, Porto Alegre, v. 2, n. 2, p. 17-26, 2001.

FERNANDEZ NETO, M.L.; SARCINELLI, P.N. Agrotóxicos em água para consumo humano: uma abordagem para avaliação de risco e contribuição ao processo de atualização da legislação brasileira. Revista Engenharia Sanitária e Ambiental, Rio de Janeiro, v. 14, n. 1, p. 69-78, 2009.

FOGG, B. J. Persuasive technology: using computers to change what we think and do. New York, Ubiquity, 2002.

FREIRE, P. Pedagogia da autonomia. São Paulo, Paz e Terra, 1997.

GATTI, B.A. Grupo focal na pesquisa em ciências sociais e humanas. Brasília, Liber Livro, 2005.

GROS, B. Videojuegos y aprendizaje. Madrid, Paidos, 2008.

GUIMARÃES, M. Educação Ambiental crítica. In: BRASIL. Ministério do Meio Ambiente (MMA). Identidades da Educação Ambiental brasileira. Brasília, MEC, 2004.

LONDRES, F. Agrotóxicos: um mal realmente necessário?. In: BRASIL. Ministério do Meio Ambiente (MMA). Fichário do Educador Ambiental. Brasília, MMA, 2015.

MANUCCI, M. Macroeducação. In: HAMMES, V. S. Proposta metodológica de macroeducação. (Org.). São Paulo, EMBRAPA, 2012.

MARIA, I.C. Agricultura e meio ambiente. Campinas: Instituto Agronômico de Campinas. Vol. 52, n.1, 2000. p.43.

MARIN, A. A. Percepção Ambiental e Imaginário dos moradores do município de Jardim/MS. 2003. 307f. Tese (Doutorado em Ecologia e Recursos Naturais) - Universidade Federal de São Carlos, 2003. 
MATOS, M.A. A metodologia de Projetos, a aprendizagem significativa e a Educação Ambiental na escola. Ensino, saúde e ambiente, Rio de Janeiro, v. 2, n. 1, p. 22-29, 2009.

MATTAR, J. Gamificação e Educação. 2015. Disponível em: $<$ http://joaomattar.com/blog/2014/03/30/gamificacao-educacao/>. Acesso em: 09 jul 2015.

MENDES, C.L. Jogos eletrônicos. Diversão, poder e subjetivação. São Paulo, Papirus, 2006.

MOITA, F. Game On: jogos eletrônicos na escola e na vida da geração. São Paulo, Editora Alínea, 2007.

MORAES, R. Análise de conteúdo. Revista Educação, Porto Alegre, v. 22, n. 37, p. 7-32, 1999.

NICOLESCU, B. O manifesto da Transdisciplinaridade. São Paulo, TRIOM, 1999.

PRENSKY, M. Aprendizagem baseada em jogos digitais. São Paulo, Senac, 2012.

RIBEIRO, W.C. Meio ambiente - em busca da qualidade de vida. In: PINSKY, C.B.; PINKY, J. (Org.). História da cidadania. São Paulo, Contexto, 2003.

SHELDON, L. The Multiplayer Classroom: Designing Coursework as a Game. Estados Unidos, Cengage Learning, 2012.

TAYLOR, D.R.F. Perspectives on Visualization and Modern Cartography. In: MACEACHREN, A.M.; TAYLOR, D.R.F. (Orgs.). Visualization In Modern Cartography. Oxford, Pergamon Press, 1994.

ZICHERMANN, G.; CUNNINGHAM, C. Gamification by Design: implementing game mechanics in web and mobile apps. Boston, O'Reilly, Sebastopol, 2011. 